\title{
Keeping chemistry in the equation
}

I n early May, a decision will be made as to whether the University of Sussex will join five other UK institutions in eliminating their chemistry departments. The staffing of the chemistry department at Sussex has been shrinking at a rapid rate in the past decade as senior faculty members have left without being replaced. The current proposal by Vice Chancellor Alistair Smith is to close the chemistry department and merge it with biology, leaving 7 of the 14 current faculty members and eliminating the undergraduate chemistry program. This trimming leaves 7 researchers in the disciplines of organic chemistry and chemical biology; inorganic and physical chemistry will be nixed.

The idea of a merger with biology is a controversial one. While at Sussex, Sir Harold Kroto, who is currently a chemistry professor at Florida State University, shared a Nobel Prize in Chemistry for the discovery of fullerenes. Citing the strength of the Sussex department, Kroto has spoken out in vehement protest of its closure. By most measures, the Sussex chemistry department is doing well. It has been the home of two other Nobel Prize winners. In the latest Research Assessment Exercise (RAE), which measures a department's performance, Sussex chemistry received the second-highest possible rating. This year, undergraduate student applications are up 40\% against a national average of $6 \%$, with some 350 students vying for 25 spaces.

So why drop a department with such credentials? According to the Vice Chancellor, it is purely a financial decision, based on the fact that the chemistry department was not attracting enough students to be viable. British universities are funded through the Higher Education Funding Council for England (HEFCE, http://www.hefce.ac.uk/), depending on their RAE ratings. However, the HEFCE is powerless in dictating how the money is distributed within a university. This responsibility is given to the Vice Chancellor of the university, who in this case is being accused of allocating money rightfully due the chemistry department to other parts of the university (http://www. rsc.org/chemistryworld/News/2006/March/29030602.asp). With recent cuts in HEFCE support, all but the top-rated universities have suffered. As HEFCE support depends on research performance, there is more and more pressure to prioritize research over teaching and, failing this, to close departments.

Although the closure of chemistry departments is confined to the $\mathrm{UK}$, the trend is disturbing to chemists worldwide and seems unlikely to halt. If the plan to close the department goes forward, as seems likely, Sussex will join Exeter, Kings College London, Queen Mary's London and Dundee in disposing of pure chemistry. Exeter recently replaced its School of Biological \& Chemical Sciences with the School of Biosciences, which includes researchers in chemical biology. The new chemical biology department at Sussex would likely be much smaller than any chemistry department would ever be, so (in theory) funding it could be easier. It is not entirely clear, however, whether this will be the case, especially if overall funding continues to decline. In addition, a loss of the chemistry department could mean a significant loss of new intellectual property income to the university.

As a chemical biology journal, we fully support the emergence of chemical biology as a field distinct from chemistry or biology, though certainly not at the expense of one or the other. The concepts and tools of both chemistry and biology are needed to make progress in chemical biology, and both fields benefit from integrated educational and collaborative efforts (see Commentary by Balch and Kelly on p. 224). Biologists realize that living systems are fundamentally grounded in chemistry, including physical chemistry and inorganic chemistry. As biologists dig deeper into organisms, organ systems, tissues and cells, they inevitably begin to look more closely at nucleic acids, proteins, metabolites and other essential chemical components of life. From this perspective, the importance of all forms of chemistry becomes obvious. For chemists, generating ties to biology brings them closer to questions about how biology is operating at a molecular level and how it might serve as an inspiration for developing and understanding new chemistries.

With the creation of dedicated chemical biology programs and departments occurring only recently, most current-day chemical biologists emerged from either one or the other traditional discipline. A good model is the chemistry department at Cambridge University, rated with the highest RAE score. One could argue that the chemical biology research at Cambridge is among the most productive generated by the department. But getting to this point was a gradual, organic process, not one that was forced or unwanted. To be sure, it included contributions from the more physically minded chemists. However, applying chemical biology to all universities as the only success model may be unrealistic. Closing departments or forcing unwanted structural changes upon chemists is likely to hurt chemical biology by fueling resentments between chemists and biologists. Chemical biology research thrives on collaboration, which depends on building positive relationships between these two scientific communities.

Although the elimination of chemistry departments has a debilitating effect on research, a long-term concern is the negative impact that the absence of traditional chemistry education may have on the next generation of chemical biologists. Chemical biology is based on the fundamentals that we teach in the traditional disciplines of organic, physical, inorganic and analytical chemistry as well as evolutionary, organismal, cellular and molecular biology. It is difficult to imagine how this multidisciplinary field can advance without educational grounding in both parent fields. The current generation of chemical biologists must actively support traditional chemistry and biology programs and find a way for the field to evolve in an environment where chemistry and biology are both flourishing. 